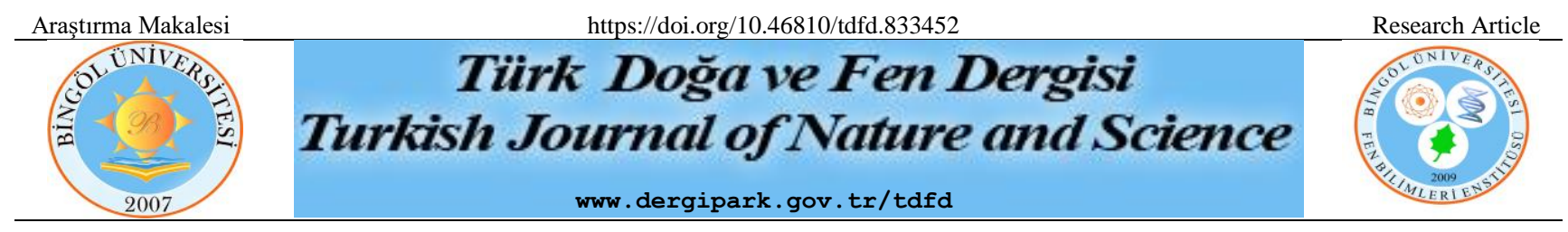

\title{
Öğrenme Eğrilerinin Karşılaştırılması
}

\author{
Uğur ATICI ${ }^{1 *}$ \\ ${ }^{1}$ Cumhuriyet Üniversitesi, Mühendislik Fakültesi, Endüstri Mühendisliği Bölümü, Sivas, Türkiye \\ Uğur ATICI ORCID No: 0000-0002-4389-9744 \\ *Sorumlu yazar: uatici@cumhuriyet.edu.tr
}

(Alınış: 30.11.2020, Kabul: 23.03.2021, Online Yayınlanma: 25.06.2021)

Anahtar
Kelimeler
Öğrenme
eğrisi,
Üretim,
Verimlilik,
Deneyim,
Optimizasyon

Öz: Şirketlerin iç ve dış süreçlerinde öğrenme eğrisi önemli bir yer tutar. Üretim sektöründe üretim miktarı veya işin tekrar sayısı arttıkça üretim süresi belirli bir oranda azalır. Bu çalışmada farklı öğrenme eğri modelleri için üretim miktarının süre üzerindeki etkisi incelenmiştir. Öğrenme eğrisi modellerinin karşılaştırılmasında kullanılan veriler Matlab 2020b programında düzgün dağılımla rastgele üretilmiştir. Üretilen veri seti, öğrenme eğrisi eşitlikleri ve literatürde önerilen katsayılar kullanılarak üretim için gerekli iş gücü süresi Matlab 2020b yazılımında hesaplanmıştır. Öğrenme eğrisi modelleri için tekrar sayısına bağlı olarak gerekli iş gücü miktarının değişimi araştırılmıştır. İncelenen tüm öğrenme modelleri, üretim miktarının artmasıyla üretim süresinin kısalacağını öngörmüştür. Üretim süresinin belirlenmesinde kullanılacak öğrenme eğrisi modeli üretim işlemine uygun olarak seçilmelidir. Birey ve grup arasında tecrübe aktarımının modellenmesine imkân tanıyan insan öğrenme optimizasyon algoritması iş postaları halinde çalışılan bakım hatlarında üretim süresinin belirlenmesine yönelik büyük bir potansiyele sahiptir.

\section{Comparison of Learning Curves}

\section{Keywords \\ Learning curve, \\ Manufacturin, Productivity, Experience, Optimization}

\begin{abstract}
The learning curve has an important place in the internal and external processes of companies. In the manufacturing sector, the production time decreases by a certain ratio as the production quantity or the number of repetitions of the job increases. In this study, the effect of production quantity on duration was examined for different learning curve models. The data used for the comparison of learning curve models were randomly generated in Matlab 2020b program with uniform distribution. The required labour force for production was calculated in Matlab 2020 b software by using the generated data set, learning curve equations and coefficients suggested in the literature. The variation of required labour force depending on the number of repetitions was examined for the learning curve models. Inspected all $t$ learning models have predicted that the production period will shorten with the increase in the production quantity. The learning curve model to be used in determining the production time should be selected in accordance with the production process. The human learning optimization algorithm, which allows the modelling of the transfer of experience between the individual and the group, has a great potential for determining the production time for maintenance lines that work as worker crew.
\end{abstract}

\section{GİRIŞ}

Günümüzde şirketlerin pazarlama, imalat ve yatırım kararlarında öğrenme eğrisi önemli bir yer tutmaktadır. Üretim sektöründe üretim miktarı arttıkça maliyetlerinin belirli bir oranda sistematik olarak azaldığı bir gerçektir [1]. Bununla beraber maliyetlerin azalmasındaki tek faktör üretim miktarı değildir. Maliyete etki eden faktörlerden bir tanesi ise öğrenme etkisidir [2].

Herhangi bir işletmede tezgâh operatüründen ve insan kaynakları birimine kadar tüm çalışanların yapmış olduğu görevin tekrar sayısına bağlı olarak çalışan performansında bir iyileşme olur. Yani birim üretim için sarf edilen çaba azalır [3]. Sarf edilen çaba ile tekrar sayısının grafiğinden elde edilecek eğri maliyet ve verimlilik açısından oldukça önemlidir. Söz konusu grafikten elde edilecek eğri literatürde öğrenme eğrisi olarak adlandırılmakla beraber kararların isabet derecesini, işlem sürelerini ve doğruluğunu etkiler [4]. $\mathrm{Bu}$ kapsamda tahmine dayalı olarak maliyetin belirlenmesinde, kapasite ihtiyacının belirlenmesinde, nakit akışının belirlenmesinde, pazar payının 
artırılmasında ve ürün çeşitliliğinin artırılmasında öğrenme eğrisi önemlidir.

$\mathrm{Bu}$ çalışmanın arkasındaki motivasyonumuz farklı disiplinler tarafindan kullanılan öğrenme eğrisi modellerine ilişkin literatür araştırmasının yapılması, son on yılda önerilen öğrenme eğrisi modelleri ile klasik öğrenme eğrisi modellerinin karşılaştırılmasıdır.

$\mathrm{Bu}$ çalışma altı bölümden oluşmuştur. Önceki çalışmaların yer aldığı literatür araştırması ikinci bölümde, literatürde öğrenme eğrisinin modellenmesi için kullanılan eşitlikler ve çalışmada kullanılan veriler üçüncü bölümde, öğrenme eğrilerinin karşılaştırılması sonucunda elde edilen bulgular dördüncü bölümde, öğrenme eğrilerinin karşılaştırma sonuçları beşinci bölümde, öğrenme eğrisinin kullanım alanları ve sonraki çalışmalar altıncı bölümde sunulmuştur.

\section{LITERATÜR ARAŞTIRMASI}

Öğrenme eğrisi literatürde ilk defa Ebbinghaus tarafından 1885 yılında incelenmiştir. Normal şartlar altında belirli bir içeriğin yeniden üretilmesi için tekrar edilmesi gerekir. Uzun söylem ve hareketlerin tek bir tekrar ile öğrenilemez [5]. Başlangıç eğrisi veya maliyet eğrisi olarak da bilinen öğrenme üretim sektöründe yaygın bir şekilde kullanılmıştır [6]. Öğrenme eğrilerinin imalat sektöründeki ilk araştırma 1936 yılında havacılık alanında Wright tarafından yapılmıştır. Önceki üretim deneyimlerine bağlı olan bir eğri tanımlanmış, hammadde, satın alma, işçilik saatleri ile maliyet arasındaki ilişkide öğrenme oranı tanımlanmıştır [2]. Üretimde maliyet çıktı miktarı ile ilgilidir. Kısa vadeli maliyetler sabit tesislerin kapasite kullanımı ile ilgili iken uzun dönemli maliyet tesisin boyut ve türündeki değişimler ile ilgilidir. Bununla beraber maliyet teknik bilgi paketlerine veya işlem tiplerine bağlıdır. Teknik bilgi değişimi maliyet fonksiyonunu ve kapasite kullanım miktarını etkiler. $\mathrm{Bu}$ doğrultuda üretim fonksiyonu teknik bilgi değişimi ile maliyet arasındaki ilişkiye bağlı olarak modellenebilir. Hirsch (1955) tarafından çalışanların teknik bilgi değişimleri ile maliyet arasındaki ilişkiye bağlı üretim fonksiyonu önerilmiştir [7]. Öğrenme eğrisi olarak anılan teknik bilgi değişimi bir üretim aracıdır [8]. Öğrenme eğrisini etkileyen faktörler aynı zamanda üretim işgücü maliyetini belirler [9]. Öğrenme, personelin gerçekleştirilen görevlere daha fazla aşina olması, muhtemel iyileştirmelerden bilgi sahibi olması, kazandığı tecrübe sayesinde takım avadanlıklara erişim/kullanım bilgisinin artması ve daha ekonomik satın almalar yapabilmesi şeklinde ortaya çıkar [10].

Öğrenme ersinin modellenmesine yönelik olarak logaritmik liner, kübik, Stanford-B, DeJong, Levy adaptasyon, Glover, Knecht ve Yelle gibi pek çok farklı model önerilmiştir [11]. Son otuz yıl içerisinde öğrenme eğrisinin farklı sektörler tarafından kullanılması ile yeni öğrenme eğrileri önerilmiştir. Önerilen bu öğrenme eğrileri üretim eğrisi modeli [12], karışık öğrenme [13], grup öğrenme $[14,15]$, pozisyon tabanlı öğrenme eğrisi $[16,17]$, insan öğrenme optimizasyon (HLO) algoritmas1
[18-20], Q öğrenme [21, 22], kuantum modeli [23], belirsiz öğrenme eğrisi[24], kanıta dayalı öğrenme [25], tek seferde öğrenme [26], MICA öğrenme eğrisi [27], bileşen tabanlı öğrenme [28] ve derin öğrenme [28-32] olarak özetlenebilir.

Öğrenme eğrisinin etkisi literatürde hava aracı tasarım değişikliklerinde [33], işlem tipine bağlı üretim fonksiyonun belirlenmesinde [34], işletmeler için kazançların belirlenmesinde [35], en uygun parti büyüklüğünün belirlenmesinde [36], hava arac1 maliyetinin belirlenmesinde [37], üretim ölçeği ve teklonoji değişiminde [38], sözleşme yapılmasında [39], kalitenin aritılmasında [40], gida servislerinde [41] incelenmiştir. Öğrenme etkisi ise yeterli gözlemsel çalışmaya dayalı olmadığı, nasıl kullanılması gerektiği hususunda yaygın bilgi olmadığı gerekçesi ile araştırmacılar tarafından eleştirilmiştir [38, 39, 42, 43].

Öğrenme eğrisi başta uçak ve otomobil montaj hatlarında olmak üzere emek yoğun endüstri kollarına incelenmiştir. Ayrıca öğrenme parametrelerinin belirlenmesi ve öğrenmenin kararlı duruma geçtiği üretim miktarı incelenen bir diğer problemdir [44]. Hava aracı imalatında maliyetlerin gerçeğe yakın olarak belirlenmesi amacı ile teknolojik büyüme kavramı ve öğrenme eğrisi kullanılmıştır [37]. Öğrenme eğrisi kalite güvence faaliyetlerini de etkiler. Kalite maliyetleri öğrenmeye bağlı olarak azalır, üretim maliyeti ise kalite maliyetlerine bağlı olarak değişir [40, 45, 46]. Bilgisayar destekli mühendislik faaliyetleri de öğrenme eğrisinden etkilenir. Öğrenme eğrisi şirket yöneticileri gelecekteki projeleri daha doğru bir şekilde tahmin etmesine imkân tanır, aynı zamanda geliştirme konseptlerin uygulanmasında ve yazılım geliştirme sürecinde iyileşme sağlar [47].

Singapur, Güney Kore ve Japonya'daki endüstriler arasında yapılan karşılaştırmada teknik bilgilerin aktarılabildiği ancak üretim ve el becerisinin pratik deneyimle (öğrenme ile) kazanıldığı bildirilmiştir [48]. İmalat endüstrisinde iş gücü öğrenmesi ile elde edilen verimlilik ve teknoloji yatırımları arasında bir ilişki vardır. Teknolojik yatırımlar ve teknoloji güncellemeler arttıkça iş gücü öğrenmesinden elde edilen verimlilik azalır [49]. Öğrenme eğrisi sürekli iyileştirme faaliyetlerini de etkiler. Yöneticiler her bir iyileştirme sonrasında endüstriyel işlemlerin verimliliğini değerlendirerek yeni iyileştirme önerileri getirir. Bu durum endüstriyel işlemlerin sürekli iyileştirmesine imkân tanır [50]. Öğrenme eğrisi teslim tarihlerinin belirlenmesinde optimal iş sıralarının belirlenmesinde yaygın olarak kullanılır. Öğrenme etkisi altında tek makine çizelgeleme [16, 24], genel iş bağımlı öğrenme ile makine çizelgeleme[51], pozisyon tabanlı öğrenme ile makine çizelgeleme [17], pozisyon tabanlı öğrenme ile paralel makine çizelgeleme [52], pozisyon tabanlı öğrenme ve risk faktörleri altında makine çizelgeleme[53, 54], pozisyon tabanlı bozulma ve öğrenme ile paralel makine çizelgeleme[55], pozisyon bağımlı öğrenme ve enerji sarfiyatı ile ilişkisiz paralel makine çizelgeleme [56], insan öğrenme optimizasyonu ile atölye çizelgeleme [57] ve derin öğrenme kümeleri ile akış çizelgeleme [29, 31] örnek olarak verilebilir. 
Öğrenme eğrisi makine çizelgelemeye benzer olarak proje çizelgeleme problemlerinde ele alınmıştır. Öğrenme eğrisi, proje çizelgelemede proje süresinin hesaplanmasinda [58], proje takvim günün hesaplanmasında [59] ve ajan tabanlı çoklu proje çizelgelemede açık artırma fiyatlarının belirlenmesinde [60] kullanılmıştır.

Son yıllarda öğrenme eğrisinin etkisi cerrahi alanda da araştırılmaktadır. Laparoskopik ameliyatlarda öğrenme eğrisi ile kan kaybı ve operasyon süresi arasında anlamlı bir farklılık vardır [61, 62]. Diş cerrahisinde öğrenme eğrisine bağlı olarak operasyon süresi azalır [63]. Robotik sol ve sağ hemiheparektomi ameliyatlarında öğrenme eğrisi hasta seçimindeki heterojenlik, cerrahın deneyimi, eğitim seviyeleri veya diğerleri gibi faktörlerin karmaşık etkileşimlerine bağlı olarak değişir [64, 65]. Transforaminal perkütan endoskopik lombar diskektomide belirli tekrar sonrasında öğrenme kararlı bir düzeye ulaşır [66]. Ayrıca öğrenme eğrisi, enerji transfer sürecinde teknik değişimlerin izlenmesi için girdi fiyatların belirlenmesinde [67], ekonomik senaryo planlamada [68], iş gücü maliyetinin azaltılmasında [69], uçak gövde maliyetinin belirlenmesinde [70], ürün montajında[71], yenilebilir enerji sistemlerinin şebeke üzerindeki etkisinin analizinde [72], sanal laboratuvar deneylerinde [73] ve maliyet/zaman optimizasyon problemlerinde [74] kullanılmıştır.

\section{MATERYAL VE METOT}

\subsection{Yöntem}

Üretim miktarına bağlı olarak gereksinim duyulan işgücü kapasitesinin belirlenmesi için pek çok farklı eşitlik önerilmiştir. $\mathrm{Bu}$ çalışmada literatürde yaygın olarak kullanılan Log-liner model [2], Crawford, Kübik [75], Seğrisi[70], Stanford-B modeli [76], DeJong öğrenme oran1 [77], Levy adaptasyon fonksiyonu [78], Crawford, Glover öğrenme oranı[79], Knecht'in yükseliş modeli [37], Yelle ürün modeli [80], Pozisyon-Bağımlı öğrenme $[16,51]$, Genel-Pozisyon-Bağımlı öğrenme[17] ve insan öğrenme optimizasyon algoritması karşılaştırılmıştır [18, 19, 81-83]. Log-liner modelde maliyet değişimi üretim miktarına bağlı olarak tanımlanmıştır (Eş.1). Uçak imalatında yapılan deneysel çalışmalardan üç farklı öğrenme oranı elde edilmiştir. Öğrenme oranı $(F)$, iş gücü için $\% 80$, hammadde kullanımı için $\% 95$, tedarik edilen malzemeler için \%88 olarak belirlenmiştir [2]. Birim üretim başına öğrenme oranı ( $\alpha=\log 0,8 / \log 2)$ işçilik için $\alpha=-0,321$, hammadde için $\alpha=-0,074$ ve tedarik edilen malzemeler için $\alpha=-0,184$ olduğu bildirilmiştir. Log-liner öğrenme modelinde işin başlangıç çevrim süresi $\left(t_{i}\right)$ ile üretim miktarı $(x)$ olmak üzere işin tamamlanması için gerekli kümülatif süre $\left(T_{x}\right)$ Eş.2 kullanılırak hesaplanır [2]. Farklı işlere üretim süresinin modellenmesine imkân tanıyan Crawford modeli için Eş.3 kullanılır [79].

$$
\begin{aligned}
\alpha & =\frac{\log F}{\log n} \\
T_{x} & =T_{i} x^{\alpha}
\end{aligned}
$$

$$
T_{x i}=T_{i} x_{i}^{\alpha}
$$

Biskup (1999) ve Mosheiev(2003) tarafindan kullanılan pozisyon bağımlı öğrenme modelinde $\mathrm{i}$ işinin süresi gerçekleştirildiği pozisyona (r) bağlı olarak hesaplanır ve Crawford (1944) öğrenme modeline oldukça benzerdir. İşin gerçekleştirildiği pozisyon aynı zamanda üretim miktarı olacağından pozisyon bağımlı öğrenme Eş.4 kullanılır [16, 51].

$$
T_{i r}=T_{i} r^{\alpha}
$$

Stanford-B modelinde öğrenme etkisi $\alpha$ 'nın -0,397 ile 0,599 arasında değiștiği kabul edilmiștir. Ancak literatürde her iki değerin ortalaması olan $-0,499$ alınması önerilmiştir. İlk çevrimin tamamlanması için gerekli süre $\left(T_{i}\right)$ uçağın ağırlığına $(W)$ bağlı olarak $\left(T_{i}=48,3 W^{0,945}\right)$ alınması önerilmiştir. $B$ sabiti ise -3 ile 179,2 arasında bir değer alır. Stanford-B modelinde kümülatif süre $T_{x}$ Eş.5 kullanılır [76].

$$
T_{x}=T_{i}(x+B)^{\alpha}
$$

Yığın üretim süreçlerinde çevrim süresindeki azalmaya bağlı olarak tecrübenin modellenmesi amacı ile DeJong öğrenme modeli önerilmiştir. İşin süresinin sıkıştırılamazlık faktörüne $\left(\mu_{D}, 0<\mu_{D}<1\right)$ bağlı olduğu ve kümülatif sürenin işin miktarına $(x)$ bağlı olarak modellenmesi gerektiği önerilmiştir. DeJong öğrenme modelinde $T_{x}$ Eş.6 kullanılarak hesaplanır [77].

$$
T_{x}=T_{i}\left(\mu_{D}+\frac{1-\mu_{D}}{x^{-\alpha}}\right)
$$

S-eğrisi sabit bir öğrenme değeri yerine üretim sayısının bașından sonuna kadar öğrenmenin değiștiğini kabul eder. Öğrenme üretimin başlangıç safhasında yavaş olmakla birlikte süreç içerisinde artar ve belli bir noktadan sonra öğrenme yavaşlar [70]. DeJong öğrenme eğrisi ile Stanford-B öğrenme eğrisinin birleşimi olan Seğrisi fonksiyonunda $M$ iş sayısı olmak üzere öğrenme oranı Eş. 7 ile üretim için gerekli süre ise olan Eş. 8 ile hesaplanır.

$$
\begin{gathered}
\alpha=\frac{\log \left(F+\tanh \left(\frac{2 x-M}{M}\right)\right)}{\log n} \\
T_{x}=T_{i}\left(\mu_{s}+\frac{1-\mu_{s}}{(x+B)^{-\alpha}}\right)
\end{gathered}
$$

Kübik model, etkinliğin tamamlanmaya yaklaştıkça önceki deneyimlerin birleşik etkisinin olduğunu ve öğrenme oranının sabit bir değer olmadığını varsayar. İlk ürünün üretim süresi $A$, kuadratik faktör $C$, kübik faktör $D$, başlangıç logartimik eğim $\alpha$ olmak üzere kübik öğrenme eğrisinde $T_{x}$ Eş.9 kullanılarak hesaplanır [75].

$$
L \log T_{x}=\log T_{i}-\alpha \log x+C(\log x)^{2}+D(\log x)^{3}
$$

Yeni işlemlerde şirketlerin performans gelişiminin modellenmesi için Levy adaptasyon fonksiyonu önerilmiştir. Şirket içi verimlilik $a=a_{0} Y_{T}^{a_{T}}(a=1,001)$, 
adaptasyon $\mu_{L}\left(\mu_{L}=\beta_{0}+\sum \beta_{T} Y_{T}\right)$, formal eğitim sayıs1 $Y_{T}$, dönemdeki eğitim katsayı $\beta_{T},-6,66 \times 10^{-4}$ ve $3,74 \times 10^{-4}$ arasında tecrübe katsayı olmak üzere Levy adaptasyon fonkisyonunda $T_{x}$ Eş.10 kullanılarak hesaplanır [78].

$$
T_{x}=T_{i}\left[l-e^{-(a+\mu x)}\right]
$$

Glover öğrenme modeli deneysel psikoloji ve gözlemlerden elde edilmiş verilere uyar. Glover öğrenme modelinde işin başlangıç zamanı $T_{0}$ olup $\mathrm{n}$ adet işin için $T_{x}$ Eş.11 kullanılarak hesaplanır [79].

$$
\sum_{i=1}^{n} T_{x}+T_{0}=T_{1}\left(\sum_{i=1}^{n} x_{i}\right)^{(1+\alpha)}
$$

Knecht yükseliş modeli üretim için gerekli iş gücü ihtiyacını belirlemek için önerilmiş bir regresyon tekniği olup büyük üretim miktarları için yükseliş sağlar. Knecht yükseliş modelinde $\mathrm{k}$ sabit bir katsayı olup $T_{x}$ Eş.12 kullanılarak hesaplanır [37].

$$
T_{x}=T_{1} x^{\alpha e^{k x}\left(k+\frac{\alpha}{x}\right)}
$$

Yelle ürün modeli farklı alt operasyonların tekrar sayısı $\left(x_{i}\right)$, süresi $\left(K_{i}\right)$ ve her bir alt operasyonu öğrenme oranı $\left(\alpha_{i}\right)$ ile x miktardaki üretim için gerekli iş gücünün $\left(T_{x}\right)$ belirlenmesine imkân tanır. Yelle ürün modelinde gerekli iş gücü Eş.13 kullanılarak hesaplanır[80].

$$
T_{x}=\sum_{i=1}^{n} K_{i} x_{i}^{\alpha_{i}}
$$

Lee (2011) tarafindan önerilen genel pozisyon bağımlı öğrenme modelinde $r^{\prime}$ inci sıradaki $i$ işinin süresi önceki işlerin öğrenme oranına $\left(\alpha_{0}=1\right),\left(0<a_{l}<1\right)$ bağlıdır ve $T_{\text {ir }}$ Eş.14 kullanılarak hesaplanır.

$$
T_{i r}=T_{i} \prod_{l=0}^{r-1} \alpha_{l}
$$

İnsan öğrenme optimizasyon algoritması (Human Learning Optimization-HLO) Wang (2014) tarafindan önerilmiştir. Bireysel tecrübenin sosyal tecrübeden etkilendiği kabul edilmiştir. Birey ve grup arasında tecrübe aktarımı gerçekleştiğinde bireyin tecrübesi grubun tecrübesine eşitlenir. $N$ problem büyüklüğü, $D$ çözüm büyüklüğü, $M$ iş sayısı ve $H$ sosyal tecrübe veritabanı büyüklüğü olmak üzere rastgele öğrenme operatörü $\left(r_{i j}\right)$ için Eş. 15, bireysel öğrenme operatörü $\left(i k d_{i}\right)$ için Eş.16 ve sosyal öğrenme operatörü $\left(s k_{q j}\right)$ için Eş.17 kullanılır. Rastgele öğrenme olasılığı $p r=$ $\left(\frac{5}{M}\right)$, bireysel öğrenmenin gerçekleşme olasılığ $p i-p r$ $(p i=0,85+2 / M)$ ve sosyal öğrenme olasılığ $1-p r$ olmak üzere $i$ inci bireyin $j$ inci çözümde öğrenme oranı $\left(\alpha_{i j}\right)$ Eş.18 kullanılarak hesaplanır[18, 19, 81-83].

$$
R_{i j}=\operatorname{Rand}(0,1)=\left\{\begin{array}{c}
0, \quad 0 \leq \operatorname{rand}() \leq 0,5 \\
1, \text { diğ } e r
\end{array}\right.
$$

$$
\begin{aligned}
& i k d_{i}=\left[\begin{array}{cccccc}
i k_{i 11} & i k_{i 12} & \cdots & i k_{i 1 j} & \cdots & i k_{i 1 D} \\
i k_{i 21} & i k_{i 22} & \cdots & i k_{i 2 j} & \cdots & i k_{i 2 D} \\
\vdots & \vdots & & \vdots & & \vdots \\
i k_{i p 1} & i k_{i p 2} & \cdots & i k_{i p j} & \cdots & i k_{i p D} \\
\vdots & \vdots & & \vdots & & \vdots \\
i k_{i L 1} & i k_{i L 2} & \cdots & i k_{i L J} & \cdots & i k_{i L D}
\end{array}\right] \\
& 1 \leq p \leq L, 1 \leq i \leq N \\
& s k_{q j}=\left[\begin{array}{cccccc}
s k_{11} & s k_{12} & \cdots & s k_{1 j} & \cdots & s k_{1 M} \\
s k_{21} & s k_{22} & \cdots & s k_{2 j} & \cdots & s k_{2 M} \\
\vdots & \vdots & & \vdots & & \vdots \\
s k_{q 1} & s k_{q 2} & \cdots & s k_{q j} & \cdots & s k_{q M} \\
\vdots & \vdots & & \vdots & & \vdots \\
s k_{i L 1} & s k_{H 2} & \cdots & s k_{H J} & \cdots & s k_{H M}
\end{array}\right] \\
& 1 \leq q \leq H \\
& \alpha_{i j}=\left\{\begin{array}{cc}
r_{i j} & 0 \leq \operatorname{rand}() \leq p r \\
i k_{i p j} & p r \leq \operatorname{rand}() \leq p i \\
s k_{q j} & \text { di } \mathrm{g} e r
\end{array}\right.
\end{aligned}
$$

\subsection{Veri}

Öğrenme eğrisi modellerinin karşılaştırılmasında kullanılan veriler Matlab 2020b programında düzgün dağılımla rastgele üretilmiştir. Öğrenme eğrilerinin karşılaştırılması için rastgele üretilen örnek veri seti Tablo 1'de, literatürden alınan katsayılar ise Tablo.2'de sunulmuştur. Log-liner, Crawford ve Pozisyon-Bağıml öğrenme modelleri için öğrenme oranı $\alpha=-0,321$ olarak alınmıştır [2]. Log-liner, Crawford ve PozisyonBağımlı öğrenme modellerinde tek bir işin gerçekleştirildiği önerildiğinden Tablo 1.'de $T_{i}$ değişkenin ortalaması olan $T=43$ dakika alınmıştır. Yelle öğrenme oranı gerçekleştirilen bir işin alt operasyonların tekrar sayısına bağlı olarak işin süresinin değiştiğini önerir [80]. Yelle (1976) çalışmasında sunulan örneğe benzer olarak işin $(n=5)$ alt operasyonlardan oluştuğu ve her bir alt operasyon süresinin eşit olduğu $K_{i}=T / 5$ kabul edilmiştir [80]. Gerçekleştirilen alt operasyonların işçilik, hammadde ve satın alınan malzeme kullanımına ilişkin olduğu, her bir alt operasyon için öğrenme oranı siras1 ile $\alpha_{1}=-0,321, \alpha_{2}=-0,074, \alpha_{3}=-0,184$, $\alpha_{4}=-0,321$ ve $\alpha_{5}=-0,074$ olduğu kabul edilmiştir [2]. Genel pozisyon bağımlı öğrenmede ilk tekrarın öğrenme oranı $\alpha_{1}=1$ sonraki tekrarların öğrenme oranı $0<a_{l}<1 a_{l}=0,321$ (l=2...20) olmas1 önerilir [17]. Kübik öğrenme eğrisinde kuadratik faktör $(C) 0,135^{\prime} \mathrm{e}$ ve kübik faktör $(D)-0,126$ 'ya eşittir [70, 75, 84]. Levy öğrenme modelinde şirket içi verimlilik $a(a=1,001)$, formal eğitim sayısı $Y_{T}\left(Y_{T}=6\right)$, dönemdeki eğitim katsayı her bir dönem için sirası ile $\beta_{1}, \beta_{2}, \beta_{3}, \beta_{4}, \beta_{5}$ ve $\beta_{6}\left(\beta_{1}=3,51 \times 10^{-4}, \beta_{2}=0, \beta_{3}=2,89 \times 10^{-4}\right.$, $\left.\beta_{4}=0 \quad, \quad \beta_{5}=-6,66 \times 10^{-4}, \beta_{6}=4,22 \times 10^{-4}\right)$. Adaptasyon katsayısı $\mu_{L}=0,712$ olduğu kabul edilmiştir [78]. DeJong öğrenme modelin sıkıştırılamazlık faktörü $\mu_{D}=0,25$ 'e eşitlenmesi önerilmiştir [55, 77]. 
Tablo 1. Örnek veri seti

\begin{tabular}{|c|c|c|c|c|c|c|c|c|c|c|c|c|c|c|c|c|c|c|c|c|}
\hline$m$ & 1 & 2 & 3 & 4 & 5 & 6 & 7 & 8 & 9 & 10 & 11 & 12 & 13 & 14 & 15 & 16 & 17 & 18 & 19 & 20 \\
\hline$T_{i}$ & 69 & 50 & 19 & 66 & 16 & 39 & 15 & 5 & 69 & 7 & 57 & 95 & 11 & 57 & 13 & 11 & 80 & 90 & 29 & 57 \\
\hline \multirow{6}{*}{$i k d_{i}$} & 0,7 & 6,8 & 0,9 & 0,8 & 1,0 & 0,5 & 0,1 & 0,1 & 0,2 & 0,4 & 0,9 & 1,0 & 0,5 & 0,3 & 0,6 & 0,7 & 0,6 & 0,7 & 0,1 & 0,1 \\
\hline & 0,8 & 0,4 & 0,9 & 0,3 & 0,3 & 0,7 & 0,7 & 0,3 & 1,0 & 0,6 & 0,8 & 0,9 & 0,7 & 0,6 & 0,9 & 0,9 & 0,1 & 0,3 & 0,7 & 0,9 \\
\hline & 0,8 & 0,4 & 0,1 & 0,4 & 0,6 & 1,0 & 0,6 & 0,6 & 0,3 & 0,3 & 0,5 & 0,6 & 0,0 & 0,8 & 0,0 & 0,1 & 0,2 & 0,1 & 0,5 & 1,0 \\
\hline & 0,3 & 0,6 & 0,7 & 0,1 & 0,8 & 0,9 & 0,4 & 0,8 & 0,7 & 0,3 & 0,8 & 0,0 & 0,4 & 0,9 & 0,7 & 0,9 & 0,3 & 0,8 & 0,1 & 0,1 \\
\hline & 0,0 & 0,8 & 0,6 & 0,3 & 0,6 & 0,8 & 0,7 & 0,2 & 0,4 & 0,9 & 0,8 & 0,2 & 0,6 & 0,8 & 0,6 & 0,6 & 0,9 & 0,8 & 0,6 & 0,4 \\
\hline & 0,6 & 0,9 & 0,1 & 0,4 & 0,3 & 0,8 & 1,0 & 0,5 & 0,4 & 0,1 & 0,2 & 0,3 & 0,3 & 0,9 & 0,2 & 0,3 & 0,1 & 0,8 & 0,8 & 0,8 \\
\hline \multirow{10}{*}{$s \boldsymbol{k}_{q j}$} & 1 & 0,7 & 0,2 & 0,5 & 0,1 & 0,4 & 0,3 & 0,9 & 0,9 & 0,4 & 0,5 & 0,3 & 0,5 & 0,7 & 0,36 & 0,82 & 0,89 & 0,29 & 0,4 & 0,26 \\
\hline & 0,1 & 0,1 & 0,6 & 0,5 & 0,1 & 0,8 & 0,5 & 0,3 & 0,9 & 0 & 0,4 & 0,2 & 0,1 & 0,9 & 0,92 & 0,43 & 0,16 & 0,45 & 0,77 & 0,7 \\
\hline & 0,1 & 0,5 & 0,6 & 0,9 & 0,8 & 0,5 & 0,4 & 0,3 & 0,6 & 0,4 & 0,3 & 0,9 & 0,6 & 0,9 & 0,47 & 0,05 & 0,53 & 0,79 & 0,94 & 0,95 \\
\hline & 0,7 & 0,1 & 0,3 & 0,3 & 0,3 & 0,2 & 1 & 0,1 & 0,7 & 0,2 & 0,8 & 0,7 & 0,4 & 0,6 & 0,45 & 0,79 & 0,46 & 0,83 & 0,13 & 0,33 \\
\hline & 0,1 & 0,1 & 0,2 & 0 & 0,2 & 0,8 & 0,6 & 0,2 & 0,4 & 0,7 & 0,1 & 0,4 & 0,6 & 0,4 & 0,96 & 0,78 & 0,28 & 0,58 & 0,66 & 0,41 \\
\hline & 0,6 & 0,3 & 0,5 & 0,5 & 0,4 & 0,4 & 0,5 & 1 & 0,1 & 0,4 & 0,5 & 0,4 & 0,1 & 0,5 & 0,63 & 0,68 & 0,8 & 0,78 & 0,08 & 0,68 \\
\hline & 0,5 & 0,1 & 0,3 & 0,6 & 0 & 0 & 0,2 & 0,6 & 0,6 & 0,9 & 0,9 & 0,5 & 0,7 & & 0,85 & 0,95 & 0,42 & 0,36 & 0,43 & 0,01 \\
\hline & 0,5 & 0,9 & 0,1 & 0,4 & 0,4 & 0,4 & 0,6 & 0,4 & 1 & 0,4 & 0,4 & 0,3 & 0,8 & 0,1 & 0,33 & 0,39 & 0,07 & 0,03 & 0,94 & 0,43 \\
\hline & 0,4 & 0,7 & 0 & 0,5 & 0,8 & 0,4 & 0,3 & 0,2 & 0,4 & 0,4 & 0,4 & 1 & 0,8 & 0,6 & 0,55 & 0,13 & 0,15 & 0,86 & 0,6 & 0,61 \\
\hline & 0,6 & 0,6 & 0,1 & 0,8 & 0,8 & 0,5 & 0,7 & 0,6 & 0,5 & 0,1 & 1 & 0,9 & 0,9 & 1 & 0,62 & 0,65 & 0,52 & 0,34 & 0,06 & 0,89 \\
\hline$R_{i j}$ & 1 & 0 & 1 & 1 & 1 & 1 & 1 & 1 & 0 & 0 & 0 & 0 & 1 & 0 & 1 & 1 & 0 & 1 & 1 & 1 \\
\hline$r_{i j}$ & 0,9 & 0,2 & 0,7 & 0,6 & 0,9 & 0,6 & 0,9 & 0,9 & 0,4 & 0,4 & 0,2 & 0,5 & 0,8 & 0,2 & 0,91 & 0,85 & 0,08 & 0,94 & 0,96 & 0,95 \\
\hline
\end{tabular}

Tablo 2. Katsayılar

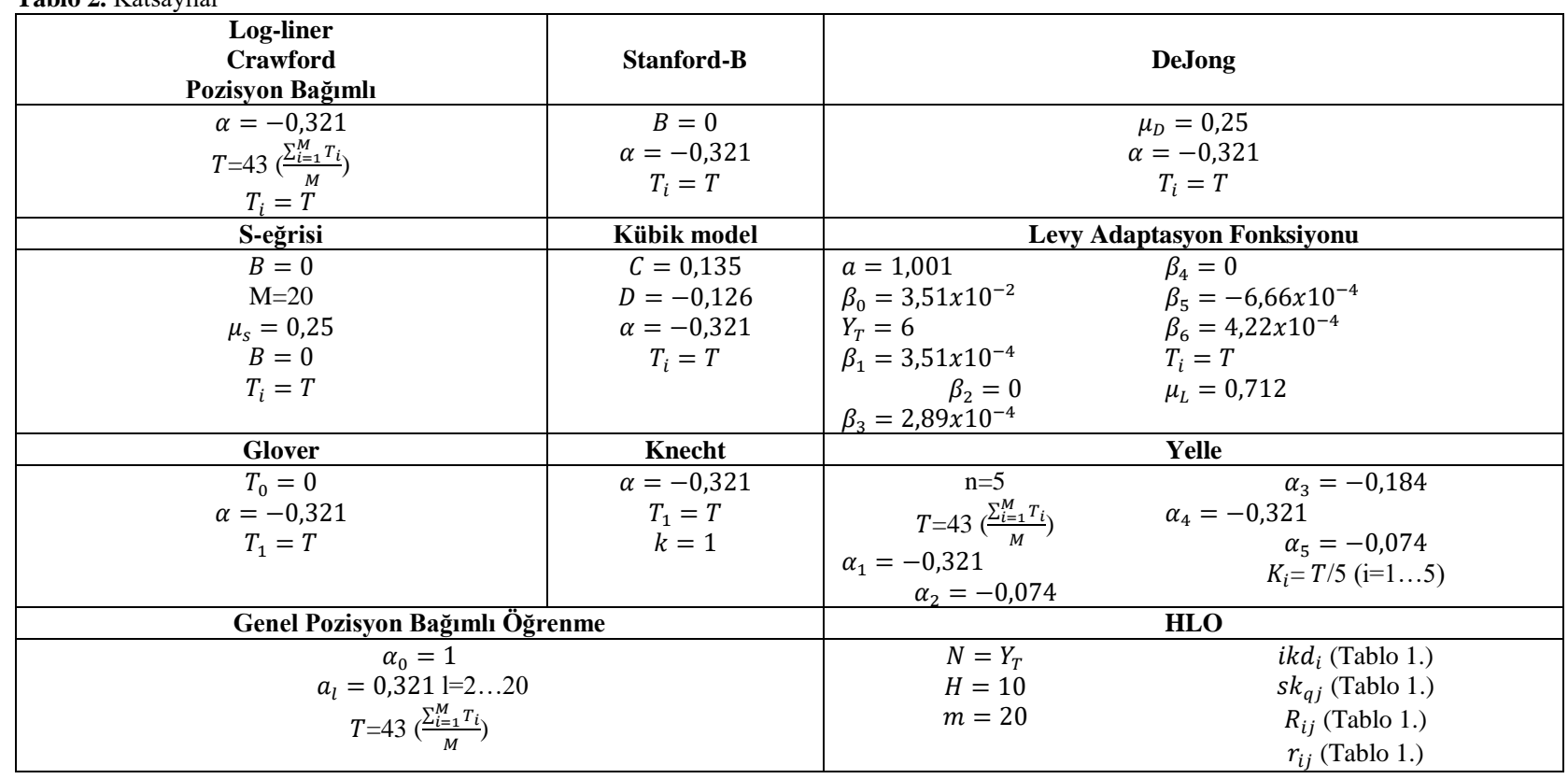

Stanford-B modelin önceki tecrübeleri temsil eden $B$ katsayısı 0'a eşittir [76]. Glover öğrenme modelinde işin başlangıç zamanı $T_{0}$ 0'a eşittir [79]. Knecht yükseliş modelinde bir sabit olan $k$ 1'e eşittir [37] . Insan öğrenme algoritmasında(HLO) üretim için gerekli süre hesabına ilişkin bir eşitlik yer almayıp, grup ve birey arasında tecrübe aktarımında öğrenme oranın belirlenmesine ilişkin bir model önerilmiştir [18, 19, 8183]. HLO algoritmasının karşılaştırılması amacı ile işçilik için gerekli süre Eş.2 kullanılarak hesaplanmıştır. Eş.2'de yer alan öğrenme oranı $(\alpha)$ yerine birey ve grup arasındaki tecrübe aktarımı sonrasındaki öğrenme oranı $\left(\alpha_{i j}\right)$ kullanılmıştır. Üretim için gerekli süre $T_{x}=T x^{\alpha_{i j}}$ ile hesaplanmıştır. Tecrübe aktarımının gerçekleşip/gerçekleşmediğine ilişkin parametre $\left(R_{i j}\right)$ bireyin rastgele öğrenme oranı $\left(i k d_{i}\right)$ ve grubun öğrenme oranı $\left(s k_{q j}\right)$ rastgele üretilmiştir.

\section{MATERYAL VE METOT}

Öğrenme oranlarının karşılaştırılması için Tablo 1.'de sunulan veriler, Tablo 2.'de sunulan katsayılar ile öğrenme eğrisi eşitlikleri (Eş1-18) kullanılarak Matlab 2020b'de gerekli iş gücü süresi hesaplanmıştır. İncelenen öğrenme modelleri için $M$ üretim miktarındaki hesaplanan üretim süreleri Tablo 3.'de sunulmuştur. Öğrenme eğrisi modelleri $T_{x}-x$ değişim grafiği Şekil 1.'de, $T_{x}-x$ karşılaştırma grafiği Şekil 2.'de sunulmuştur. Öğrenme modelleri ile hesaplanan üretim 
süreleri ortalama, standart sapma, varyans, en kısa ve en büyük üretim süreleri Tablo 4.'te sunulmuştur.

Log-Liner, Crawford, Pozisyon Bağımlı ve Stanford-B öğrenme eğrisi modelleri için miktara bağlı olarak eşit üretim süresi önermiştir. Log-Liner, Crawford, Pozisyon Bağımlı ve Stanford-B modelleri M üretim miktarı için gerekli üretim süresinin ortalaması $\left(\overline{T_{x}}\right)$ 22,6 dakika, standart sapması $(\sigma)$ 6,8 dakika, varyans $\left(\sigma^{2}\right)$ 46,6 dakika olarak hesaplanmıştır. $M=1$ için $T_{x}=43$ dakika, $M=20$ adet için $\left(T_{x}\right) \quad 16,4$ dakika olarak hesaplanmıştır.

DeJong öğrenme eğrisi modelinde $M$ üretim miktarı için gerekli üretim süresinin ortalaması $\left(\overline{T_{x}}\right)$ 27,7 dakika, standart sapması $(\sigma)$ 5,1 dakika, varyans $\left(\sigma^{2}\right)$ 26,5 dakika olarak hesaplanmıştır. $M=1$ için $T_{x}=43$ dakika, $M=20$ adet için $T_{x}=23$ dakika olarak hesaplanmıştır.

Tablo 3. Hesaplanan üretim süreleri $(T x)$ (dakika)

\begin{tabular}{|c|c|c|c|c|c|c|c|c|c|c|c|c|c|}
\hline$M$ & 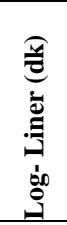 & 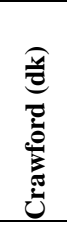 & 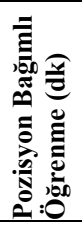 & 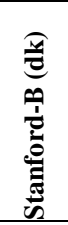 & 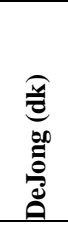 & 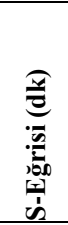 & 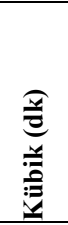 & $\begin{array}{l}\text { 全 } \\
\text { 它 }\end{array}$ & $\begin{array}{l}\text { 일 } \\
\vdots \\
\frac{0}{0}\end{array}$ & 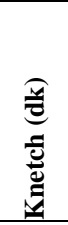 & 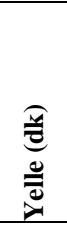 & 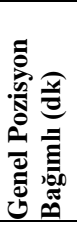 & 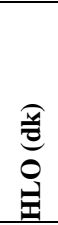 \\
\hline 1 & 43,0 & 43,0 & 43,0 & 43,0 & 43,0 & 43,0 & 43,0 & 43,0 & 43,0 & 43,0 & 43,0 & 43,0 & 43,0 \\
\hline 2 & 34,4 & 34,4 & 34,4 & 34,4 & 37,0 & 34,0 & 39,4 & 43,0 & 30,2 & 25,7 & 37,7 & 13,8 & 23,5 \\
\hline 3 & 30,2 & 30,2 & 30,2 & 30,2 & 33,0 & 31,0 & 16,2 & 42,0 & 24,2 & 18,1 & 35,0 & 4,5 & 15,2 \\
\hline 4 & 27,5 & 27,5 & 27,5 & 27,5 & 31,0 & 29,0 & 4,3 & 42,0 & 20,5 & 14,0 & 33,2 & 1,4 & 11,5 \\
\hline 5 & 25,6 & 25,6 & 25,6 & 25,6 & 30,0 & 27,0 & 0,9 & 42,0 & 18,0 & 11,5 & 31,9 & 0,5 & 8,9 \\
\hline 6 & 24,2 & 24,2 & 24,2 & 24,2 & 29,0 & 27,0 & 0,2 & 41,0 & 16,1 & 9,7 & 30,9 & 0,1 & 7,5 \\
\hline 7 & 23,0 & 23,0 & 23,0 & 23,0 & 28,0 & 26,0 & 0,0 & 41,0 & 14,7 & 8,5 & 30,1 & 0,0 & 6,4 \\
\hline 8 & 22,0 & 22,0 & 22,0 & 22,0 & 27,0 & 26,0 & 0,0 & 40,0 & 13,6 & 7,5 & 29,4 & 0,0 & 5,6 \\
\hline 9 & 21,2 & 21,2 & 21,2 & 21,2 & 27,0 & 26,0 & 0,0 & 40,0 & 12,6 & 6,7 & 28,8 & 0,0 & 5,0 \\
\hline 10 & 20,5 & 20,5 & 20,5 & 20,5 & 26,0 & 26,0 & 0,0 & 39,0 & 11,8 & 6,1 & 28,3 & 0,0 & 4,5 \\
\hline 11 & 19,9 & 19,9 & 19,9 & 19,9 & 26,0 & 26,0 & 0,0 & 39,0 & 11,2 & 5,6 & 27,9 & 0,0 & 4,1 \\
\hline 12 & 19,3 & 19,3 & 19,3 & 19,3 & 25,0 & 27,0 & 0,0 & 38,0 & 10,6 & 5,2 & 27,5 & 0,0 & 3,8 \\
\hline 13 & 18,8 & 18,8 & 18,8 & 18,8 & 25,0 & 27,0 & 0,0 & 37,0 & 10,1 & 4,8 & 27,1 & 0,0 & 3,5 \\
\hline 14 & 18,4 & 18,4 & 18,4 & 18,4 & 25,0 & 27,0 & 0,0 & 37,0 & 9,6 & 4,5 & 26,8 & 0,0 & 3,3 \\
\hline 15 & 18,0 & 18,0 & 18,0 & 18,0 & 24,0 & 28,0 & 0,0 & 36,0 & 9,2 & 4,2 & 26,5 & 0,0 & 3,1 \\
\hline 16 & 17,6 & 17,6 & 17,6 & 17,6 & 24,0 & 28,0 & 0,0 & 35,0 & 8,8 & 4,0 & 26,2 & 0,0 & 2,9 \\
\hline 17 & 17,3 & 17,3 & 17,3 & 17,3 & 24,0 & 28,0 & 0,0 & 34,0 & 8,5 & 3,8 & 26,0 & 0,0 & 2,7 \\
\hline 18 & 17,0 & 17,0 & 17,0 & 17,0 & 23,0 & 28,0 & 0,0 & 33,0 & 8,2 & 3,6 & 25,7 & 0,0 & 2,6 \\
\hline 19 & 16,7 & 16,7 & 16,7 & 16,7 & 23,0 & 29,0 & 0,0 & 32,0 & 7,9 & 3,4 & 25,5 & 0,0 & 2,4 \\
\hline 20 & 16,4 & 16,4 & 16,4 & 16,4 & 23,0 & 29,0 & 0,0 & 31,0 & 7,7 & 3,3 & 25,3 & 0,0 & 2,3 \\
\hline
\end{tabular}

Glover öğrenme modelinde $M$ üretim miktarı için gerekli üretim süresinin ortalaması $\left(\overline{T_{x}}\right)$ 14,8 dakika, standart sapması $(\sigma)$ 8,9 dakika, varyans $\left(\sigma^{2}\right) 79,4$ dakika olarak hesaplanmıştır. $M=1$ için $T_{x}=43$ dakika, $M=20$ adet için $T_{x}=7,7$ dakika olarak hesaplanmıştır. Her iki değer en büyük ve en küçük değerler olup 1'inci ve 20'inci sıradaki işlere aittir.
S-Eğrisi öğrenme modelinde $M$ üretim miktarı için gerekli üretim süresinin ortalaması $\left(\overline{T_{x}}\right)$ 28,6 dakika, standart sapması $(\sigma)$ 3,9 dakika, varyans $\left(\sigma^{2}\right)$ 15,3 dakika olarak hesaplanmıştır. $M=1$ için $T_{x}=43$ dakika, $M=10$ adet için $T_{x}=26$ dakika olarak hesaplanmıştır.

Kübik öğrenme modelinde $M$ üretim miktarı için gerekli üretim süresinin ortalaması $\left(\overline{T_{x}}\right) 5,2$ dakika, standart sapması $(\sigma)$ 12,9 dakika, varyans $\left(\sigma^{2}\right)$ 165,4 dakika olarak hesaplanmıştır. $M=1$ için $T_{x}=43$ dakika, $M=20$ adet için $T_{x}=0$ dakika olarak hesaplanmıştır.

Levy öğrenme modelinde $M$ üretim miktarı için gerekli üretim süresinin ortalaması $\left(\overline{T_{x}}\right) 38,3$ dakika, standart sapması $(\sigma)$ 3,7 dakika, varyans $\left(\sigma^{2}\right)$ 14,0 dakika olarak hesaplanmıştır. $M=1$ için $T_{x}=43$ dakika, $M=20$ adet için $T_{x}=31,0$ dakika olarak hesaplanmıştır. Her iki değer en büyük ve en küçük değerler olup 1'inci ve 20'inci sıradaki işlere aittir.
Knetch öğrenme modelinde $M$ üretim miktarı için gerekli üretim süresinin ortalaması $\left(\overline{T_{x}}\right)$ 9,7 dakika, standart sapması $(\sigma)$ 9,7 dakika, varyans $\left(\sigma^{2}\right) 94,2$ dakika olarak hesaplanmıştır. $M=1$ için $T_{x}=43$ dakika, $M=20$ adet için $T_{x}=3,3$ dakika olarak hesaplanmıştır. 

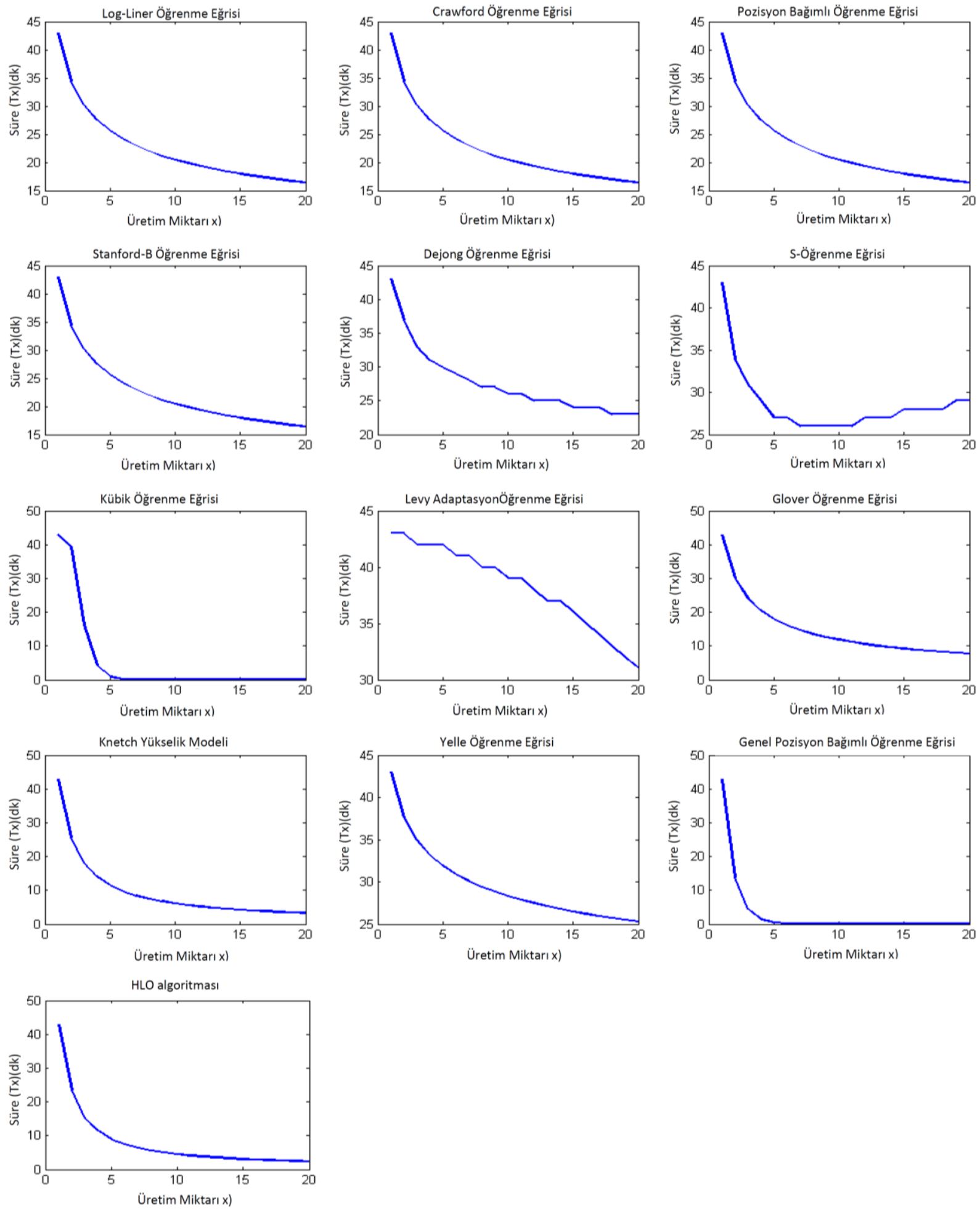

Şekil 1. Öğrenme eğrisi modelleri $T x-x$ değişim grafiği

Yelle öğrenme modelinde $M$ üretim miktarı için gerekli üretim süresinin ortalaması $\left(\overline{T_{x}}\right)$ 29,6 dakika, standart sapması $(\sigma)$ 4,6 dakika, varyansı $\left(\sigma^{2}\right)$ 21,2 dakika olarak hesaplanmıştır. $M=1$ için $T_{x}=43$ dakika, $M=20$ adet için $T_{x}=25,3$ dakika olarak hesaplanmıştır.

Genel-Pozisyon-Bağımlı öğrenme modelinde $M$ üretim miktarı için gerekli üretim süresinin ortalaması $\left(\overline{T_{x}}\right) 3,2$ dakika, standart sapması $(\sigma)$ 9,9 dakika, varyansı $\left(\sigma^{2}\right)$
98,0 dakika olarak hesaplanmıştır. $M=1$ için $T_{x}=43$ dakika, $M=20$ adet için $T_{x}=0$ dakika olarak hesaplanmıştır. Her iki değer en büyük ve en küçük değerler olup 1'inci ve 20'inci sıradaki işlere aittir. 
Tablo 4. Öğrenme modelleri üretim süreleri karşılaștırma

\begin{tabular}{|c|c|c|c|c|c|}
\hline Öğrenme Modeli & $\overline{\boldsymbol{T}}$ & $\boldsymbol{\sigma}$ & $\boldsymbol{\sigma}^{\mathbf{2}}$ & $\begin{array}{c}\text { En } \\
\text { küçük }\end{array}$ & $\begin{array}{c}\text { En } \\
\text { büyük }\end{array}$ \\
\hline Log Liner & 22,6 & 6,8 & 46,6 & 16,4 & 43,0 \\
\hline Crawford & 22,6 & 6,8 & 46,6 & 16,4 & 43,0 \\
\hline Pozisyon-Bağımlı & 22,6 & 6,8 & 46,6 & 16,4 & 43,0 \\
\hline Stanford-B & 22,6 & 6,8 & 46,6 & 16,4 & 43,0 \\
\hline DeJong & 27,7 & 5,1 & 26,5 & 23,0 & 43,0 \\
\hline S-Eğrisi & 28,6 & 3,9 & 15,3 & 26,0 & 43,0 \\
\hline Kübik & 5,2 & 12,9 & 165,4 & 0,0 & 43,0 \\
\hline Levy & 38,3 & 3,7 & 14,0 & 31,0 & 43,0 \\
\hline Glover & 14,8 & 8,9 & 79,4 & 7,7 & 43,0 \\
\hline Knetch & 9,7 & 9,7 & 94,2 & 3,3 & 43,0 \\
\hline Yelle & 29,6 & 4,6 & 21,2 & 25,3 & 43,0 \\
\hline $\begin{array}{c}\text { Genel-Pozisyon- } \\
\text { Bağımlı }\end{array}$ & 3,2 & 9,9 & 98,0 & 0,0 & 43,0 \\
\hline HLO & 8,1 & 9,7 & 95,1 & 2,3 & 43,0 \\
\hline
\end{tabular}

HLO öğrenme modelinde $M$ üretim miktarı için gerekli üretim süresinin ortalaması $\left(\overline{T_{x}}\right) 8,1$ dakika, standart sapması $(\sigma)$ 9,7 dakika, varyans $\left(\sigma^{2}\right)$ 95,1 dakika olarak hesaplanmıştır. $M=1$ için $T_{x}=43$ dakika, $M=20$ adet için $T_{x}=0$ dakika olarak hesaplanmıştır.

İncelenen öğrenme modellerinin tümü miktara bağlı azalan üretim süresi önermiştir. Kübik öğrenme eğrisi ile Genel-Pozisyon-Bağımlı öğrenme eğrisi miktar bağlı olarak üretim süresini sıfıra eşit olacağını önermektedir.

S-Eğrisi öğrenme modeli ile DeJong öğrenme modeli $\mathrm{M}=11$ için üretim süreleri kesişmiştir ( $T x=26$ dakika). Benzer olarak S-Eğrisi öğrenme modeli ile Yelle öğrenme modeli $\mathrm{M}=13$ için üretim süreleri eşittir $\left(T_{x}\right.$ $=27$ dakika).

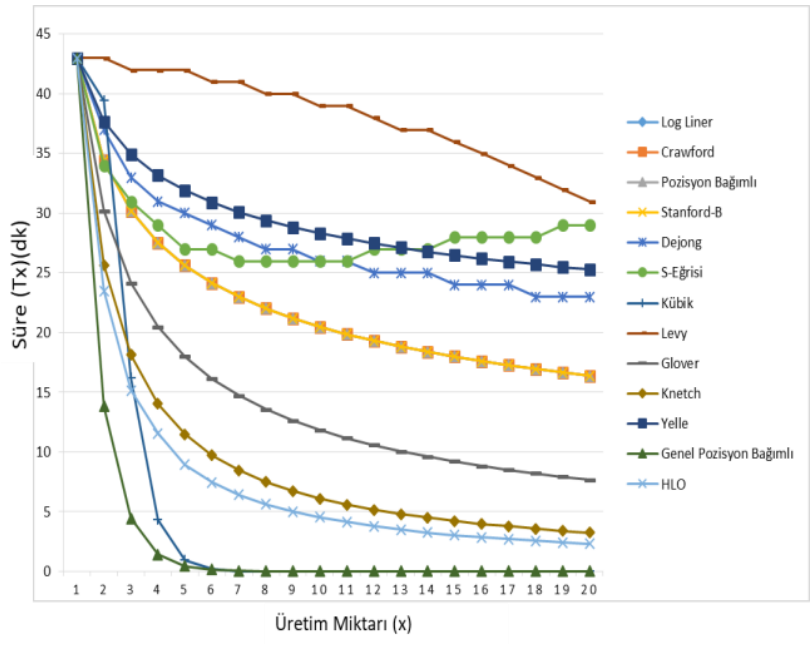

Şekil.2 Öğrenme eğrisi $(T x \& x)$ modelleri karşıllaştırma grafiği

\section{SONUC}

Bu çalışmada literatürde yer alan öğrenme eğri modelleri için farklı üretim miktarının üretim süresime etkisi incelenmiştir. Literatürdeki önerilen 13 farklı öğrenme modelinin karşılaştırılması için 20 farklı işe ait standart zaman bilgisi rastgele üretilmiştir. Matlab 2020b yazılımında her bir öğrenme eğrisi modeli için literatürde önerilen katsayılar kullanılarak üretim miktarına bağlı olarak gerekli iş gücü miktarının değişimi incelenmiştir.

Geçmiş tecrübeleri modellemek için kullanılan B katsayısı 0'a eșit alındığında Stanford-B öğrenme eğrisi modeli Log-Liner, Crawford ve Pozisyon Bağımlı öğrenme $\mathrm{M}$ üretim miktarına bağlı olarak eşit üretim süresinin eşit olur. Crawford, Pozisyon Bağımlı ve Stanford-B öğrenme eğrileri Log-liner öğrenme eğrisinden farklı olarak standart zamanları değişik işlere ait üretim sürelerinin hesaplanmasına imkân tanır.

DeJong öğrenme eğrisi $M$ üretim miktarı için gerekli üretim süre ortalaması ( $\overline{T x}=27,7$ dakika) Log-Liner, Crawford, Pozisyon Bağımlı ve Stanford-B öğrenme modellerinden $(\overline{T x}=16,4$ dakika $)$ daha yüksel olmakla beraber standart sapması ( $\sigma=5,1$ dakika) daha düşüktür. S-Eğrisi öğrenme modeli üretim devam ettikçe öğrenmedeki değişimi kullanarak üretim süresinin belirlenmesine imkân tanımakla beraber $(M=1$ için $T x=43$ dakika, $M=10$ adet için $T x=26$ dakika, $M=20$ adet için $T x=29$ dakika) öğrenme oranının değişimini belirlemek oldukça güçtür. Kübik öğrenme modeli ve Genel-Pozisyon Bağımlı öğrenme $M=7-$ 20 adet için $T x=0$ dakika olduğundan emek yoğun üretim süreçlerinin modellenmesinin kullanımı uygun değildir.

Glover, Knetch ve HLO öğrenme modelleri ile $M=20$ adet için sırası ile üretim süresi 7,7 dakika 3,3 dakika ve 2,3 dakika olarak hesaplanmıştır. Yelle öğrenme modeli $(\overline{T x})$ 29,6 dakika olmasına rağmen standart sapması $(\sigma)$ 4,6 dakika olarak gerçekleşmiştir.

İncelenen öğrenme modellerinin tümü miktara bağlı azalan üretim süresi önermiştir. S-Eğrisi öğrenme modeli ile DeJong öğrenme modeli $\mathrm{M}=11$ için, S-Eğrisi öğrenme modeli ile Yelle öğrenme modeli $\mathrm{M}=13$ için eş üretim süreleri öngörmüştür.

\section{TARTIŞMA}

Üretim işlemlerinde tekrar sayısına bağlı olarak gerekli işgücünün belirlenmesinde literatürdeki öğrenme modellerinden üretim işlemine uygun olanı seçilmelidir. Genel-pozisyon-bağımlı öğrenme modelinin 5 inci tekrardan sonra gerekli süreyi 0 ' eşit kabul ettiğinden üretim işlemlerinin süresinin belirlenmesinde kullanımı uygun değildir.

İnsan öğrenme algoritmasında (HLO) bireyde öğrenmenin gerçekleşip/gerçekleşmediğine bağlı olarak grup ve birey arasında öğrenmenin aktarıldığı kabul edilmiştir. Bununla beraber birey ve grup arasında öğrenme aktarımın gerçekleştiği durumda bireyin öğrenmesinin grub içindeki en yüksek öğrenme oranına sahip bireyin tecrübe seviyesine eşit olduğu kabul edilmiştir. Ancak bakım sektöründe çırak veya kalfaların tecrübe seviyesi ustanın tecrübesine tek bir eğitim tekrarı ile eşitlenmez. Kalfa ve çırağın öğrenmesi grup içindeki en iyi tecrübe düzeyine sahip olan usta ile beraber çalışma sayısına bağlı olarak zaman içerisinde artar. 
Savunma sanayinde silah sistemlerin bakım onarımları iş postaları adı verilen çalışma grupları ile gerçekleştirilir. İş postalarında farklı tecrübe seviyesine sahip bireyler birlikte çalışırlar. HLO öğrenme modelinde birey ve grup arasında rastgele tecrübe aktarımı yerine tekrar sayısına bağlı olarak grup içinde bireylerin tecrübe artışı olacak şekilde modellenmesi durumunda HLO algoritmasının sonraki varyasyonlarının depo seviyesi bakım hatlarında kullanım potansiyeli oldukça yüksektir. Bununla birlikte HLO'nun gelecek varyasyonlarında Yelle öğrenme modelinde olduğu gibi alt operasyonlarındaki öğrenme oranlarının hesaba katılması ile fabrika seviyesi bakım hatlarında üretim için gerekli iş gücü miktarı gerçeğine yakın bir şekilde hesaplanabilir.

\section{KAYNAKLAR}

[1] Li B, Ji Q, Arreola-Risa A. Optimizing a production-inventory system under a cost target. Computers \& Operations Research. 2020;123:105015.

[2] Wright TP. Factors affecting the cost of airplanes. Journal of the Aeronautical Sciences. 1936;3:122-8.

[3] Anzanello MJ, Fogliatto FS. Learning curve models and applications: Literature review and research directions. International Journal of Industrial Ergonomics. 2011;41(5):573-83.

[4] Kortge GD, Okonkwo PA, Burley JR, Kortge JD. Linking experience, product life cycle, and learning curves: Calculating the perceived value price range. Industrial Marketing Management. 1994;23(3):2218.

[5] 5Ebbinghaus H. Memory: a contribution to experimental psychology. Annals of neurosciences. 2013;20(4):155-6.

[6] Pegels CC. On Startup or Learning Curves: An Expanded View. A I I E Transactions. 1969;1(3):216-22.

[7] Hirsch WZ. Manufacturing Progress Functions. The Review of Economics and Statistics. 1952;34(2):143-55.

[8] Andress FJ. The Learning Curve as a Production Tool: Harvard University; 1954.

[9] Lundberg RH. Learning Curve Theory as Applied to Production Costs. SAE International. 1956;64:775-81.

[10] Carlson JG. How Management Can Use the Improvement Phenomenon. California Management Review. 1961;3(2):83-94.

[11] Badiru AB. Manufacturing cost estimation: A multivariate learning curve approach. Journal of Manufacturing Systems. 1991;10(6):431-41.

[12] Badiru AB. Multivariate Learning Curve Model for Manufacturing Economic Analysis. In: Parsaei HR, Mital, A, editor. Economics of Advanced Manufacturing Systems. Boston, MA: Springer; 1992.

[13] Thomopoulos NT, Lehman M. The Mixed Model Learning Curve. A I I E Transactions. 1969;1(2):127-32.

[14] Argote L, Insko C, Yovetich N, Romero A. Group Learning Curves: The Effects of Turnover and Task
Complexity on Group Performance1. Journal of Applied Social Psychology. 1995;25:512-29.

[15] Peltokorpi J, Jaber MY. A group learning curve model with motor, cognitive and waste elements. Computers \& Industrial Engineering. 2020;146:106621.

[16] Biskup D. Single-machine scheduling with learning considerations. European Journal of Operational Research. 1999;115(1):173-8.

[17] Lee W-C. Scheduling with general position-based learning curves. Information Sciences. 2011;181(24):5515-22.

[18] Wang L, Ni H, Yang R, Fei M, Ye W. A Simple Human Learning Optimization Algorithm2014. 56$65 \mathrm{p}$.

[19] Wang L, Pei J, Menhas MI, Pi J, Fei M, Pardalos PM. A Hybrid-coded Human Learning Optimization for mixed-variable optimization problems. Knowledge-Based Systems. 2017;127:114-25.

[20] Shoja A, Molla-Alizadeh-Zavardehi S, Niroomand S. Hybrid adaptive simplified human learning optimization algorithms for supply chain network design problem with possibility of direct shipment. Applied Soft Computing. 2020;96:106594.

[21] Wei Z, Zhang Y, Xu X, Shi L, Feng L. A task scheduling algorithm based on Q-learning and shared value function for WSNs. Computer Networks. 2017;126:141-9.

[22] Wei Z, Liu F, Zhang Y, Xu J, Ji J, Lyu Z. A Qlearning algorithm for task scheduling based on improved SVM in wireless sensor networks. Computer Networks. 2019;161:138-49.

[23] Wene C-O. Quantum modelling of the learning curve. Futures. 2018;103:123-35.

[24] Li Y, Yang X, Yang Z. Uncertain learning curve and its application in scheduling. Computers \& Industrial Engineering. 2019;131:534-41.

[25] Valsamis E, Sukeik M. Evaluating learning and change in orthopaedics: What is the evidence-base? World Journal of Orthopaedics. 2019;10.

[26] Zhang L, Liu J, Luo M, Chang X, Zheng Q, Hauptmann AG. Scheduled sampling for one-shot learning via matching network. Pattern Recognition. 2019;96:106962.

[27] Palmanovich E, Ohana N, Atzmon R, Slevin O, Brin Y, Feldman V, et al. MICA: A Learning Curve. The Journal of Foot and Ankle Surgery. 2020;59(4):781-3.

[28] Kang J-N, Wei Y-M, Liu L, Han R, Chen H, Li J, et al. The Prospects of Carbon Capture and Storage in China's Power Sector under the $2{ }^{\circ} \mathrm{C}$ Target: A Component-based Learning Curve Approach. International Journal of Greenhouse Gas Control. 2020;101:103149.

[29] Zhou P, He X, Luo S, Yu H, Sun G. JPAS: Jobprogress-aware flow scheduling for deep learning clusters. Journal of Network and Computer Applications. 2020;158:102590.

[30] Wang H, Wu Y, Min G, Xu J, Tang P. Data-driven dynamic resource scheduling for network slicing: A Deep reinforcement learning approach. Information Sciences. 2019;498:106-16. 
[31] Luo S. Dynamic scheduling for flexible job shop with new job insertions by deep reinforcement learning. Applied Soft Computing. 2020;91:106208.

[32] Tong Z, Chen H, Deng X, Li K, Li K. A scheduling scheme in the cloud computing environment using deep Q-learning. Information Sciences. 2020;512:1170-91.

[33] Garg A, Milliman P, editors. The aircraft progress curve modified for design changes 1961.

[34] Nadler G, Smith WD. Manufacturing Progress Functions for Types of Processes. International Journal of Production Research. 1963;2(2):115-35.

[35] Hirschmann WB. Profit from the Learning Curve. Profit from the Learning Curve. 1964;2.

[36] Keachie EC, Fontana RJ. Effects of Learning on Optimal Lot Size. Management Science. 1966;13(2):B-102-B-8.

[37] Knecht GR. Costing, Technological Growth and Generalized Learning Curves. Journal of the Operational Research Society. 1974;25(3):487-91.

[38] Montgomery D, Day G. Diagnosing the Experience Curve. Journal of Marketing. 1983;47.

[39] Yelle L. Common Flaws in Learning Curve Analysis. Journal of Purchasing and Materials Management. 1985;21:10-5.

[40] Fine CH. Quality Improvement and Learning in Productive Systems. Management Science. 1986;32(10):1301-15.

[41] Reis DA. Learning Curves in Food Services. The Journal of the Operational Research Society. 1991;42(8):623-9.

[42] Jordan RB. How to Use the Learning Curve: Materials Management Institute; 1965.

[43] Baloff N. The Learning Curve--Some Controversial Issues. The Journal of Industrial Economics. 1966;14(3):275-82.

[44] Baloff N. Extension of the Learning Curve Some Empirical Results. Journal of the Operational Research Society. 1971;22(4):329-40.

[45] Badiru AB. Quality improvement through learning curve analysis. In: Handbook of Total Quality Management. Boston, MA: Springer; 1998.

[46] Jaber MY, Glock CH, Zanoni S. A Learning Curve with Improvement in Process Quality. IFACPapersOnLine. 2018;51(11):681-5.

[47] Kemerer C. How the Learning Curve Affects CASE Tool Adoption. IEEE Software. 1992;9:238.

[48] Heng TM, Low L. Estimating and comparing learning curves in three Asian economies. Asia Pacific Journal of Management. 1995;12(1):21-35.

[49] Klenow P. Learning Curves and the Cyclical Behavior of Manufacturing Industries. Review of Economic Dynamics. 1998;1:531-50.

[50] Zangwill W, Kantor P. Toward a Theory of Continuous Improvement and the Learning Curve. Management Science. 1998;44:910-20.

[51] Mosheiov G, Sidney JB. Scheduling with general job-dependent learning curves. European Journal of Operational Research. 2003;147(3):665-70.

[52] Lee W-C, Chuang M-C, Yeh W-C. Uniform parallel-machine scheduling to minimize makespan with position-based learning curves. Computers \& Industrial Engineering. 2012;63(4):813-8.

[53] Senyigit E, Atici U, editors. Scheduling with Job Dependent Learning Effect and Ergonomic Risk Deterioration. 2018 2nd International Symposium on Multidisciplinary Studies and Innovative Technologies (ISMSIT); 2018 19-21 Oct. 2018.

[54] Şenyiğit E, Atici U, Şenol MB. Effects of OCRA parameters and learning rate on machine scheduling. Central European Journal of Operations Research. 2020.

[55] Li K, Chen J, Fu H, Jia Z, Wu J. Parallel machine scheduling with position-based deterioration and learning effects in an uncertain manufacturing system. Computers \& Industrial Engineering. 2020;149:106858.

[56] Soleimani H, Ghaderi H, Tsai P-W, Zarbakhshnia N, Maleki M. Scheduling of unrelated parallel machines considering sequence-related setup time, start time-dependent deterioration, positiondependent learning and power consumption minimization. Journal of Cleaner Production. 2020;249:119428.

[57] Ding H, Gu X. Hybrid of human learning optimization algorithm and particle swarm optimization algorithm with scheduling strategies for the flexible job-shop scheduling problem. Neurocomputing. 2020;414:313-32.

[58] Malyusz L. Learning Curve Effect on Project Scheduling. Procedia Engineering. 2016;164:90-7.

[59] Mályusz L, Varga A. An Estimation of the Learning Curve Effect on Project Scheduling with Calendar Days Calculation. Procedia Engineering. 2017;196:730-7.

[60] Tosselli L, Bogado V, Martínez E. A repeatednegotiation game approach to distributed (re)scheduling of multiple projects using decoupled learning. Simulation Modelling Practice and Theory. 2020;98:101980.

[61] Li Z, Ye Y, Wu Z, Wang B. Learning Curve Analysis of Laparoscopic Kasai Portoenterostomy. Journal of Laparoendoscopic \& Advanced Surgical Techniques. 2017;27.

[62] Feldman LS, Cao J, Andalib A, Fraser S, Fried GM. A method to characterize the learning curve for performance of a fundamental laparoscopic simulator task: Defining "learning plateau" and "learning rate". Surgery. 2009;146(2):381-6.

[63] Son K, Lee K-B. Prediction of learning curves of 2 dental CAD software programs, part 2: Differences in learning effects by type of dental personnel. The Journal of Prosthetic Dentistry. 2020;123(5):74752.

[64] Alikhanov R. An Invited Commentary on: "Comparison of the learning curves for robotic left and right hemiheparectomy: A prospective cohort study". (International journal of surgery 2020; 81:19-25. International Journal of Surgery. 2020;83:140.

[65] Liu Q, Zhang T, Hu M, Zhao Z, Zhao G, Li C, et al. Comparison of the learning curves for robotic left and right hemihepatectomy: A prospective cohort 
study. International Journal of Surgery. 2020;81:19-25.

[66] Ahn Y, Lee S, Son S, Kim H, Kim JE. Learning Curve for Transforaminal Percutaneous Endoscopic Lumbar Discectomy: A Systematic Review. World Neurosurgery. 2020;143:471-9.

[67] Zhou D, Ding H, Zhou P, Wang Q. Learning curve with input price for tracking technical change in the energy transition process. Journal of Cleaner Production. 2019;235:997-1005.

[68] Ramirez R, Bhatti Y, Tapinos E. Exploring how experience and learning curves decrease the time invested in scenario planning interventions. Technological Forecasting and Social Change. 2020;151:119785.

[69] Ören K, Erol M. Learning Curves, Usage Of Learning Curves in Reducing Workforce Costs As A Tool and An Empriical Study. Frrat University Journal of Social Science 2009;19(1):133-41.

[70] Moore JR. A Comparative Study of Learning Curve Models in Defense Airframe Cost Estimating. Wright-Patterson Air Force Base Ohio: Department of The Air Force Air University; 2015.

[71] Mark BG, Rauch E, Matt DT. Study of the impact of projection-based assistance systems for improving the learning curve in assembly processes. Procedia CIRP. 2020;88:98-103.

[72] Hong S, Yang T, Chang HJ, Hong S. The effect of switching renewable energy support systems on grid parity for photovoltaics: Analysis using a learning curve model. Energy Policy. 2020;138:111233.

[73] Francis S, Kolil V, Achuthan K. Learning curve analysis for virtual laboratory experimentation 2016.

[74] Abdelkhalek HA, Refaie HS, Aziz RF. Optimization of time and cost through learning curve analysis. Ain Shams Engineering Journal. 2020.

[75] Thomas HR, Mathews CT, Ward JG. Learning Curve Models of Construction Productivity. Journal of Construction Engineering and Management. 1986;112(2):245-58.

[76] Asher H. Cost-Quantity Relationships in the Airframe industry. Santa Monica: The Rand Corporation; 1956.

[77] De Jong JR. The Effects of Increasing Skill on Cycle Time And Its Consequences for Time Standards. Ergonomics. 1957;1(1):51-60.

[78] Levy FK. Adaptation in the Production Process. Management Science. 1965;11(6):B-136-B-54.

[79] Glover JH. Manufacturing progress functİons I. An alternative model and Its comparİson with existing functions. International Journal of Production Research. 1965;4(4):279-300.

[80] Yelle LE. Estimating learning curves for potential products. Industrial Marketing Management. 1976;5(2):147-54.

[81] Wang L, Ni H, Yang R, Pardalos PM, Du X, Fei M. An adaptive simplified human learning optimization algorithm. Information Sciences. 2015;320:126-39.
[82] Wang L, Yang R, Ni H, Ye W, Fei M, Pardalos PM. A human learning optimization algorithm and its application to multi-dimensional knapsack problems. Applied Soft Computing. 2015;34:73643.

[83] Wang L, Pei J, Wen Y, Pi J, Fei M, Pardalos PM. An improved adaptive human learning algorithm for engineering optimization. Applied Soft Computing. 2018;71:894-904.

[84] Ralli P, Panas A, Pantouvakis J-P, Karagiannakidis D. Investigation and Comparative Analysis of Learning Curve Models on Construction Productivity: The Case of Caisson Fabrication Process. Journal of Engineering, Project, and Production Management. 2020;10(3):219-30. 